\title{
Influence of strain history on the mechanical and micro-fabric evolution of calcite rocks: insights from torsion experiments
}

Journal Article

Author(s):

Delle Piane, Claudio; Burlini, Luigi

Publication date:

2008-09

Permanent link:

https://doi.org/10.3929/ethz-b-000157883

Rights / license:

In Copyright - Non-Commercial Use Permitted

Originally published in:

Swiss Journal of Geosciences 101(2), https://doi.org/10.1007/s00015-008-1257-1 


\title{
Influence of strain history on the mechanical and micro-fabric evolution of calcite rocks: insights from torsion experiments
}

\author{
Claudio Delle Piane*,1 \& Luigi Burlini
}

Key words: Calcite, experimental deformation, rheology, strain history, microstructure, crystallographic preferred orientation

\begin{abstract}
Different types of deformation experiments were conducted on specimens of Carrara marble at a temperature of $1000 \mathrm{~K}, 300 \mathrm{MPa}$ confining pressure, and $3 \times 10^{-4} \mathrm{~s}^{-1}$ shear strain rate. Microstructural examinations were carried out using light and electron microscopy. Fabric analysis was performed through electron backscattered diffraction (EBSD) measurements. The stress-strain relationships from the experiments indicate that the mechanical response of Carrara marble depends on the deformation history. After a first ductile deformation event the marble becomes permanently softened and is able to undergo plastic strain at relatively lower stresses compared to previously undeformed marble. After shear strain reversal of $\gamma=2$ or less the original microstructure is restored; in highly re-strained samples $(\gamma= \pm 3,4$ and 5) dynamic recrystallization mechanisms create an evident foliation whose angle in
\end{abstract}

respect to the shear plane defines a shear sense criterion which is in agreement with the reversed sense of shearing. After a minimum shear strain reversal of $\gamma=3$ the pre-existing foliation is totally overprinted. The fabric produced during strain reversal experiments shows features, which are comparable with those of single-stage experiments; but the strength of the crystallographic preferred orientation (CPO) is significantly lower, indicating complex microstructural interactions during plastic reactivation.

Our tests indicate that the strain weakening in Carrara marble is predominantly caused by grain size refinement through dynamic recrystallization. The development of a crystallographic preferred orientation contributes towards only about one third of the total weakening observed.

\section{Introduction}

The dynamics of lithosphere deformation is believed to be characterized by the localization of plastic flow of rocks into shear zones. Plate tectonics itself is based on the idea that the largest tectonic displacements are attained in narrow plastic zones both in the middle and lower crust and in the lithospheric mantle. For their characteristics these shear zones are suitable sites for stable, localized plastic deformation or for subsequent preferred reactivation, due to the fact that they are mechanically weaker than their protholiths.

Experimental deformation studies have normally been coupled and interpreted trough microstructural investigations and texture analyses; and in field based studies, textures were often used to derive the strain history or the strain geometry which the investigated rocks underwent (e.g. Burkhard 1990; Burkhard 1993; Bestmann et al. 2000; Ebert et al. 2007; Austin et al. 2008-this volume). Laboratory investigations demonstrated that the strength of a rock evolves progressively during large plastic strain, and that microstructural and textural evo- lution as a function of strain observed in the laboratory appears to closely approximate those, which are inferred to occur in nature. Large strain experiments established a strong link between the microstructural evolution of geological materials with strain and their mechanical behaviour. In particular a number of studies on Carrara marble pointed out that, at conditions in which dislocation creep is the dominant deformation mechanism, strain weakening may be linked to dynamic recrystallization to a finer grain size and/or to the development of a strong lattice preferred orientation (LPO) (Rutter et al. 1994; Rutter 1995; Pieri et al. 2001a; Barnhoorn et al. 2004).

Strain weakening in these experiments usually was interpreted as being due to either grain size refinement (via grain boundary migration and subgrain rotation recrystallization) or strain dependent fabric organization, processes that have frequently been regarded separately. In many different materials dynamic recrystallization by grain boundary migration causes a relevant softening of the aggregate which can be attributed to the replacement of a strain-hardened structure by softer dislocation-free one (Poirier 1985). In the case of subgrain rotation

Geological Institute ETH Leonhardstrasse, 19/LEB CH-8092 Zürich Switzerland.

${ }^{1}$ Now at: CSIRO Petroleum Resources, Australian Resources Research Centre, 26 Dick Perry Avenue, Kensington 6151 Western Australia.

*Corresponding author: C. Delle Piane. E-mail: claudio.dellepiane@csiro.au 
recrystallization the progressive organization of free dislocations with increasing strain would result in a polygonization of the substructures and in a decrease of stored energy making the material easier to deform. Owing to the fact that dynamic recrystallization generally causes the grain size to reduce, it has been suggested (Twiss 1976; Schmid 1982; Rutter \& Brodie 1988 ) that creep mechanisms of minerals in geological settings leading to recrystallization might change from power-law creep to grain-size-dependent creep, active in fine-grained materials. Such a switch has been confuted for single phase materials (De Bresser et al. 1998; De Bresser et al.2001) on the basis that new grains produced by dynamic recrystallization may initially be sufficiently small to deform by grain-size-sensitive creep, but will subsequently grow until dislocation processes become significant again. The resulting grain size will therefore represent a balance between grain size reduction mechanisms (e.g. subgrain rotation recrystallization, bulging nucleation) and grain growth via grain boundary migration (e.g. Means \& Xia 1981; Herwegh \& Handy 1996). The observed weakening of dynamically recrystallized materials would then arise from a major contribution of diffusion creep, besides dislocation creep, on the bulk strain rate of the deforming aggregate. For example Ter Heege et al. (2002) explained the observed weakening of axially compressed Carrara marble as a result of an increase of the contribution of grain size sensitive deformation mechanisms to the overall creep rate, due to the nucleation of small grains by dynamic recrystallization. As a consequence changes in the bulk flow stress can be attributed to changes in grain size distribution.

Large strain torsion experiments on Carrara marble showed that strain weakening is associated with a refreshment of the microstructure by grain size refinement, but also with the development of a CPO characterized by $\mathrm{r}<\mathrm{a}>$ and $\mathrm{c}<\mathrm{a}>$ preferred orientations aligned for easy slip. It is worth noting that easy slip preferred orientations have been observed after simple shear deformation of calcite (Schmid et al. 1987; Pieri et al. 2001b; Barnhoorn et al. 2004), quartz (Dellangelo \& Tullis 1989) olivine (Zhang \& Karato 1995; Bystricky et al. 2000), and ice (Burg et al. 1986), as well as during in-situ rock analogue experiments (e.g. Herwegh \& Handy 1996; Herwegh et al.1997; Herwegh \& Handy 1998).

Microstructural features from deformation experiments are used to interpret microstructures in naturally strained rocks. Geologists assume that the final observable microstructure represents the microstructure formed during the last increment of deformation. However, the deformation phase of interest has been overprinted by other thermal or tectonic events. Little is known about the effect of dynamic recrystallization on an already existing LPO. Large strain deformation and annealing experiments on quartz (Heilbronner \& Tullis 2002), calcite (Barnhoorn et al. 2005) and on analogue materials (Herwegh \& Handy 1996; Ree \& Park 1997; Park et al. 2001) helped to relate different types of annealing behaviour to the dynamic recrystallization processes active during deformation. Most of those experiments had in common a rapid overprint of the de- formational microstructures. Typically, the deformational CPO weakened but the CPO type remained unchanged during annealing.

The present study extends the earlier works on experimental deformation of Carrara marble with the aim of answering the following key questions:

- How do the steady state mechanical properties of mylonites compare with those of the protholiths the mylonites were derived from?

- May dynamic recrystallisation alone lead to localisation of strain in a monophase material?

- What microstructural information can we infer from a material, which underwent multiple deformation events?

\section{Experimental procedure}

The studied material was Carrara marble, a well-known material for rock mechanics tests. It is considered to be a standard for laboratory studies due to its chemical and microstructural features. The marble consists of $\sim 98 \%$ pure calcite with occasional grains of quartz, dolomite, muscovite and graphite (e.g. Pieri et al. 2001a). The starting material shows little evidence of any preferred orientation and is characterized by a homogeneous grain size distribution with a mean grain diameter of $150 \mu \mathrm{m}$ and is therefore considered to be isotropic. Specimens were drilled from the same block of Lorano Bianco type described by Pieri et al. (2001a). Deformation experiments were performed on cylindrical samples of $15 \mathrm{~mm}$ diameter and approx. $10 \mathrm{~mm}$ length. The planar cylinder surfaces were machined parallel to each other and oriented perpendicular to the cylinder axis by precision polishing. All samples were oven-dried at $120^{\circ} \mathrm{C}$ for at least 24 hours before testing.

Deformation experiments were performed in torsion at high temperature and high pressure in an internally heated gas apparatus (Paterson \& Olgaard 2000) using inert high-purity argon as a confining medium. Torque was applied to the samples through an external actuator, and measured via an internal load cell with an accuracy of $\pm 0.2 \mathrm{Nm}$; the angular displacement was recorded by a rotational variable differential transformer (RVDT). The temperature distribution inside the furnace was regularly calibrated so that the thermal profile along the sample length was stable within $\pm 1 \mathrm{~K}$. Temperature during the experiments was monitored using a K-type thermocouple placed at $3 \mathrm{~mm}$ from the top surface of the sample.

Cylindrical samples of $15 \mathrm{~mm}$ in diameter were inserted in iron jackets with wall thickness of $0.25 \mathrm{~mm}$, in order to isolate the specimen from the confining medium. Each specimen was sandwiched between alumina spacers of the same diameter. Partially stabilized zirconia pistons were inserted between the top and bottom steel pistons and the alumina spacers in order to optimize the thermal profile of the column and minimize conductive heat losses (Paterson \& Olgaard 2000). The jacket and the specimen assembly were sealed with O-rings against the steel end pieces. 


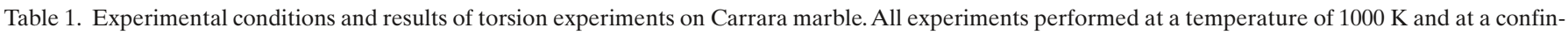

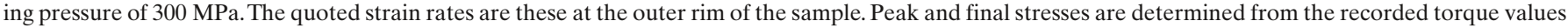
using a stress exponent $n$ of 10 as discussed in the text.

\begin{tabular}{|c|c|c|c|c|c|c|c|}
\hline Run \# & $D(\mathbf{m m})$ & $\mathbf{L}(\mathbf{m m})$ & Shear Strain & $\begin{array}{l}\text { Shear Strain } \\
\text { rate }\left(s^{-1}\right)\end{array}$ & $\begin{array}{l}\text { Peak shear } \\
\text { stress (MPa) }\end{array}$ & $\begin{array}{l}\text { Final shear } \\
\text { stress (MPa) }\end{array}$ & $\begin{array}{l}\text { Type of } \\
\text { experiment }\end{array}$ \\
\hline PO577 & 15 & 10 & 1 and -1 & $3 \times 10^{-4}$ & 60.1 & 56.4 & Type 1 \\
\hline PO583 & 15 & 10.5 & 2 and -2 & $3 \times 10^{-4}$ & 48.3 & 46.5 & Type 1 \\
\hline PO586 & 15 & 10 & 5 and -5 & $3 \times 10^{-4}$ & 49.4 & 41.1 & Type 1 \\
\hline PO632 & 15 & 9.8 & 3 and -3 & $3 \times 10^{-4}$ & 48.1 & 43.8 & Type 1 \\
\hline PO638 & 15 & 9.9 & 4 and -4 & $3 \times 10^{-4}$ & 50.3 & 45.5 & Type 1 \\
\hline PO767 & 15 & 10.1 & 5 & $3 \times 10^{-4}$ & 61.9 & 41.9 & Type 1 \\
\hline PO772 & 15 & 9 & 1 & $1 \times 10^{-4}$ & 52.6 & 47.9 & Type 2 \\
\hline \multirow[t]{2}{*}{ PO852 } & 14.8 & 10.2 & 5 & $3 \times 10^{-4}$ & 59.8 & 46 & Type 3 \\
\hline & & & 4.4 & $3 \times 10^{-4}$ & 55.7 & 45.5 & Type 3 \\
\hline
\end{tabular}

Shear strain rate, temperature and confining pressure were chosen to reproduce previously explored experimental conditions (Pieri et al. 2001 a; Barnhoorn et al. 2004) allowing direct comparison with the new results. Tests were conducted at $1000 \mathrm{~K}$ and $300 \mathrm{MPa}$ up to different amounts of shear strain. All runs were performed at constant angular displacement rates corresponding to shear strain rates of $3 \times 10^{-4} \mathrm{~s}^{-1}$ at the outer radius of the samples.

Three types of experiments were performed:

\section{- Type I experiments:}

Five samples were subject to two deformation events within an identical kinematic framework, but by reversing the shearing direction in order to investigate the influence of a previously developed fabric on the rheological response and on the final microfabric of the marble. First, the specimens were deformed to a given amount of strain; then the sense of torsion was inverted and the samples loaded again and deformed up to an equal but opposite amount of shear strain. The unloading and re-loading procedure was carried out during the same run within a few seconds in order to avoid annealing of the microstructures.

\section{- Type II experiments:}

To test the influence of both previously strain-induced grain size reduction and pre-existing fabric evolution on strain localization, a composite sample, consisting of a layer of previously deformed and undeformed Carrara marble, was prepared and deformed. The pre-deformed layer was manufactured previously by straining it in torsion up to shear strain of $\gamma=5$ at $1000 \mathrm{~K}$ and at a shear strain rate of $3 \times 10^{-4} \mathrm{~s}^{-1}$. The composite specimen was then jacketed and deformed at the same conditions of temperature and pressure as the other experiments.

\section{- Type III experiments:}

To additionally test the role of grain size and CPO on the steady state properties of calcite, a sample was first deformed to a shear strain $\gamma=5$ whereby it obtained a strong CPO and a fine grain size of about $30 \mu \mathrm{m}$ due to dynamic recrystallisation; see Pieri et al. (2001) and Barnhoorn et al. (2004). The same specimen was then statically annealed for 5 hours at the same temperature of $1000 \mathrm{~K}$ so that the grain size coarsened while the CPO underwent only minor changes, as was demonstrated by Barnhoorn et al. (2005). Subsequently, the deformation was started again, still under the same conditions that prevailed prior to annealing. The sequence of deformation, static annealing and re-deformation, was carried out at constant temperature and confining pressure by switching on or off the torsion actuator during the same test and on one and the same single sample to avoid variations in strength due to sample variability and specimen re-jacketing.

All experimental conditions and sample geometries are summarized in Table 1.

The recorded torque was converted into shear stress following the relationship (Paterson \& Olgaard 2000):

$$
M=\frac{\tau 2 \pi R^{3}}{3+\frac{1}{n}}
$$

Where $M$ is the torque, $\tau$ is the shear stress and $R$ is the radius of the sample. An arbitrary value of the stress exponent $(n)$ of 10 was used, following the considerations of Pieri et al. (2001) and Barnhoorn et al. (2004) in order to have a direct comparison with the results of these studies.

\section{Microstructural analysis}

Thin sections were cut from the deformed samples for quantitative microstructural analysis. Since the amount of strain linearly increases from zero in the centre of the cylindrical sample to a maximum at the rim, thin sections were taken close to the outer radius of each specimen and parallel to the cylinder axis. Here the shear direction is approximately parallel to the horizontal axis of the section so that the microstructural information is expressed in the same reference frame as the one commonly used for studies of naturally deformed mylonites. All sections were prepared ultra-thin $(<10 \mu \mathrm{m})$ and polished on both sides. 


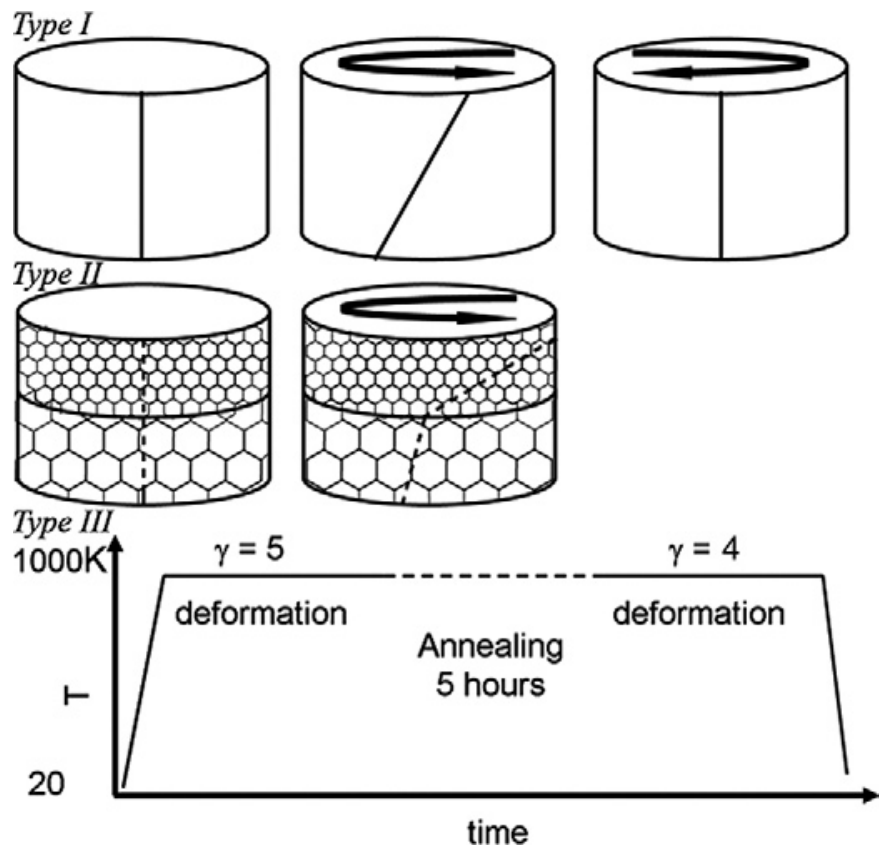

Fig. 1. Sketches of the types of performed tests.

Type I: Each sample was subject to two straining events with identical shear plane but opposite sense of shear during one single test. Solid lines across the samples represent strain markers (see text).

Type II: A slice of previously strained and dynamically recrystallized Carrara marble is placed on top of a slice of "as is" material; the whole assemblage is then strained in torsion.

Type III: Plot of temperature versus time. Temperature was raised at a rate of $20 \mathrm{~K} / \mathrm{min}$ until $1000 \mathrm{~K}$, then deformation started with a shear strain rate of $3 \times 10^{-4} \mathrm{~s}^{-1}$ and continued up to a shear strain of $\gamma=5$. The sample was then unloaded and kept in static conditions for 5 hours at constant temperature and confining pressure. Afterwards deformation started again with a reversed shear strain rate of $3 \times 10^{-4} \mathrm{~s}^{-1}$ and continued up to a reversed shear strain of $\gamma=4$.

2-D analyses of grain size and shape were performed on digital images of optical micrographs of thin sections by manually tracing the grain boundaries. The binary outline grain boundaries images were then thresholded and analyzed using UTHSCSA ImageTool. Grain sizes $d$ were calculated from the measured areas assuming $d$ as the diameter of a circle with the same area of the grain in question. Two-dimensional grain size distributions were then plotted in histograms representing the number and area weighted distributions.

\section{Electron backscatter diffraction}

Automated electron backscatter diffraction (EBSD) analyses of the deformed samples were performed in a CamScan CS44LB scanning electron microscope (SEM) at sample portions as close as possible to the outer rim. Rectangular sampling grids were defined on the specimens with a step size according to the optically estimated grain size. This procedure allowed measuring any grain size population ranging from very small to large grain sizes. Each specimen was me- chanically polished using a succession of finer abrasive papers and subsequently diamond paste with a finer particle size of $1 \mu \mathrm{m}$. The polishing procedure was completed by lapping the samples for approximately 1 hour with an alkaline colloidal silica suspension (particle size $25 \mathrm{~nm}$ ). Lapped samples were coated with approximately $4 \mathrm{~nm}$ thick carbon layer and tilted in the SEM chamber at an angle of $20^{\circ}$ to the incident beam. Working conditions were $35 \mathrm{~mm}$ working distance and $15 \mathrm{kV}$ accelerating voltage. Electron backscattered patterns were automatically collected and indexed from probed areas of approx. $6 \times 7 \mathrm{~mm}$ using the commercial TSL software OIM. Contoured pole figures were calculated excluding data with an ambiguous indexing (confidence index $<0.1$ ). Contouring of the discrete data was carried out using a Gaussian convolution with a half width of $15^{\circ}$ and the maximum order of the spherical harmonic function $(L)$ was set to 32 . CPO strength was calculated as texture index $J$.

\section{Results}

\section{Mechanical behaviour}

\section{Type I experiments}

The stress strain curves of the performed experiments are illustrated in Figs. 2a-b. In agreement with previous studies (Pieri et al, 2001; Barnhoorn at al, 2004) all the experiments showed similar shear stress - shear strain behaviour, the reproducibility of the stress value for experiments run at the same conditions of temperature and shear strain rate was within $10 \mathrm{MPa}$. At $1000 \mathrm{~K}$ and with a shear strain rate of $3 \times 10^{-4} \mathrm{~s}^{-1}$ Carrara marble strain hardens up to a peak stress of $53 \pm 6 \mathrm{MPa}$ reached at $\gamma \approx 1$ (Fig. 2a). A pronounced weakening is observed with increasing strain, and at shear strains between 4 and 5 the shear stress stabilizes to a constant value (mechanical steady state) of $46 \pm 6 \mathrm{MPa}$. When the sense of shear was reversed the sample was first unloaded then loaded again in the opposite direction; the mechanical response is illustrated in Figure 2b. Generally the shear stress value reached after inversion was the same as that reached before inversion within $\pm 3 \mathrm{MPa}$, the stress strain curve is very similar to that of classic large strain experiments. Hence, if weakening was occurring during the first deformation event (e.g. $\gamma=1$ and $\gamma=2$ experiments) it also continued after the sense of shear was reversed. Whereas if mechanical steady state was reached during the first deformation event, the shear stress did not change after strain reversal with increasing strain (e.g. $\gamma=3,4$ and 5 experiments).

\section{Type II experiments}

To reduce the possibility of slip due to the mechanical discontinuity at the interface between the two layers of the composite sample the experiment was run at a slightly slower shear strain rate $\left(1 \times 10^{-4} \mathrm{~s}^{-1}\right)$ compared to the rest of the experiments $\left(3 \times 10^{-4} \mathrm{~s}^{-1}\right)$. 

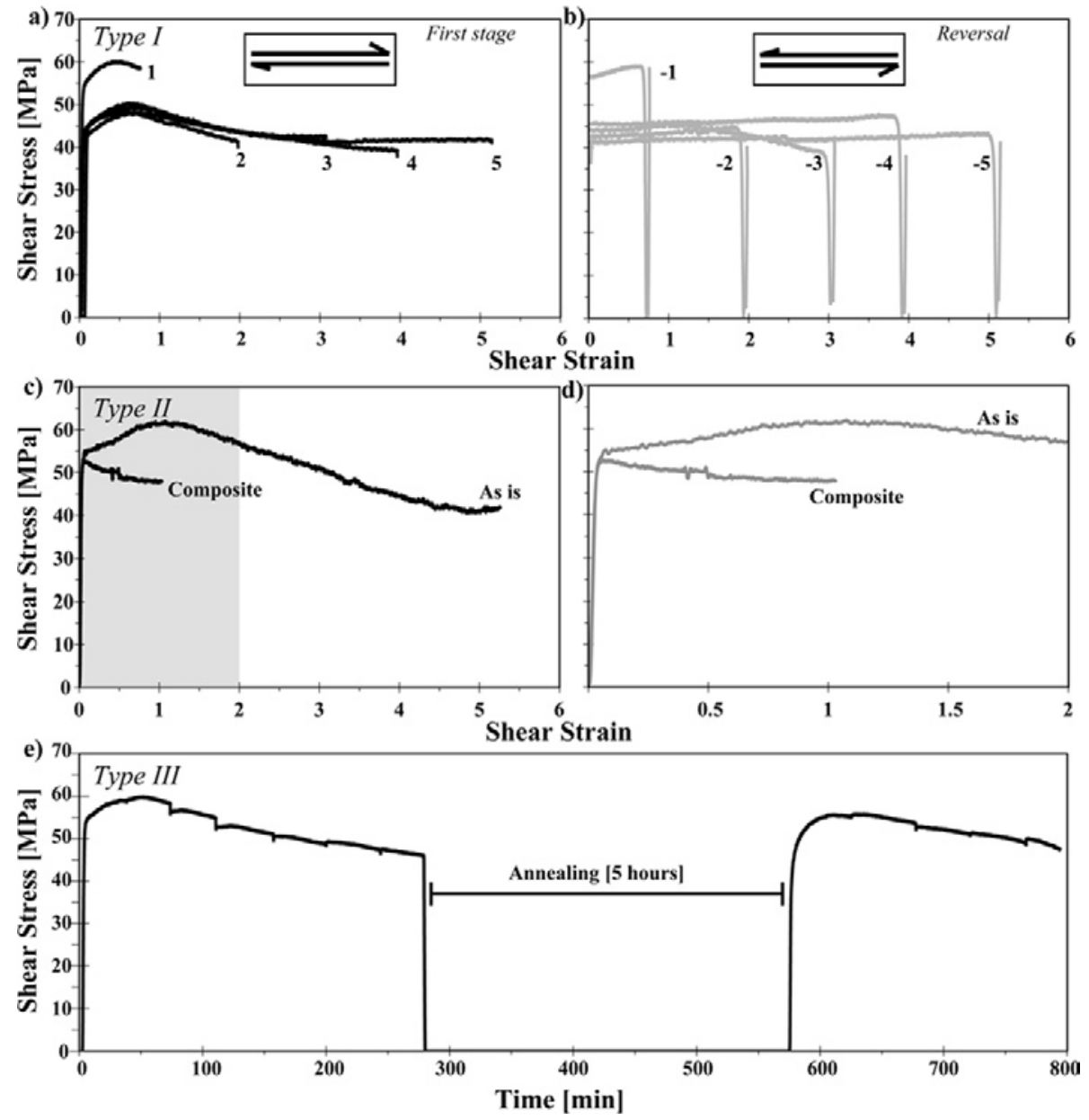

Fig. 2. Stress versus strain/time of the preformed tests.

Fig. 2a \& b: Type I tests. Shear stress as a function of strain for different experiments performed at $1000 \mathrm{~K}$ and $3 \times 10^{-4} \mathrm{~s}^{-1}$. The left and right plots represent the first and second deformation events respectively. Sense of shear is marked by the arrows in the inlets. Each curve is labelled after the amount of shear strain attained during the test. Positive numbers are indicated for the first stage runs; negative numbers are used for the strain reversal part of the tests.

Fig. 2c \& d: Type II tests. Comparison between "as is" and composite sample strength. The shaded area is enlarged in (d).

Fig. 2e: Type III test. Shear stress as function of time at constant temperature. The sample was unloaded during five hours of static annealing and then loaded again. Both deformation events took place under a constant shear strain rate of $3 \times 10^{-4} \mathrm{~s}^{-1}$.
The stress strain behaviour is illustrated in Figs. 2c-d: in contrast with classic torsion experiments (Pieri et al. 2001a, Barnhoorn et al. 2004), the shear stress of the composite specimen reaches a steady value after a relatively small amount of shear strain, without showing the characteristic hardening behaviour at low strains. The composite specimen slowly weakens, finally reaching a stable value at a shear strain of ca. 0.5. Despite the slower strain rate the attained steady value compares very well with that of the shear stress of Carrara marble deformed at larger strains, in agreement with previously reported mechanical results on the deformation behaviour of Carrara marble (Barnhoorn et al. 2004).

\section{Type III experiments}

To mitigate the influence of sample variability on the interpretation of the stress results we run the type III experiment (load - anneal - load) on one single specimen without taking it out of the experimental apparatus. In this way the only uncertainty is that related to the resolution in the internal torque cell $(\Delta \mathrm{M}$ $\pm 0.5 \mathrm{Nm}$ ), which corresponds, to a shear stress resolution $(\Delta \tau)$ of $\pm 1 \mathrm{MPa}$ i.e. $3 \%$ of the reported yield stress of $35 \mathrm{MPa}$. The uncertainty is smaller than the measured stress variation, which hence can be largely attributed to the microstructural evolution of the sample.

\section{Type I}

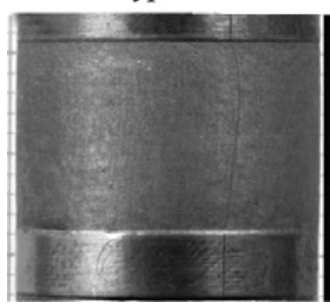

Type II

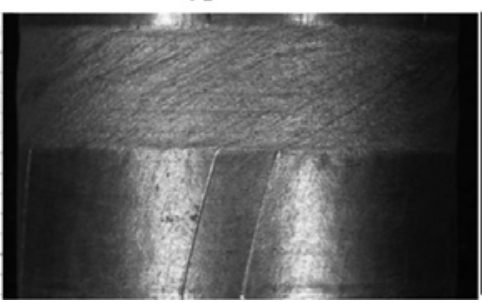

Type III

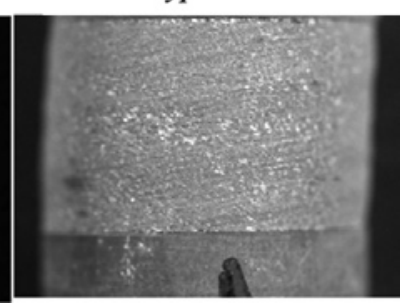

Fig. 3. Photographs of deformed specimens inside the iron jacket. Type I (PO577) test: Strain is almost homogeneous as indicated by the nearly vertical scratch on the surface of the jacket used as a passive strain marker. Type II (PO772): Shear strain is strongly partitioned between the top and bottom layer of the composite sample. The previously deformed layer on top was able to accommodate a shear strain 9 times greater than the bottom layer. Type III test (PO852): The wrinkles on the outer surface of the jacket show constant inclination along the specimen length indicating homogeneous deformation. 
The experimental sequence was as follows: 0-280 minutes leading to a first deformation event, 280-580 minutes static annealing, 580 minutes renewed loading and deformation during which continuous weakening occurred (Fig. 2e). The peak stress of the post-annealing loading is $7 \%$ lower than the peak stress obtained before annealing. The final stresses of the pre- and post-annealing deformations are $23 \%$ and $18 \%$ lower than the respective peak stresses. The difference in final stresses before and after annealing is only ca. $0.5 \mathrm{MPa}$.
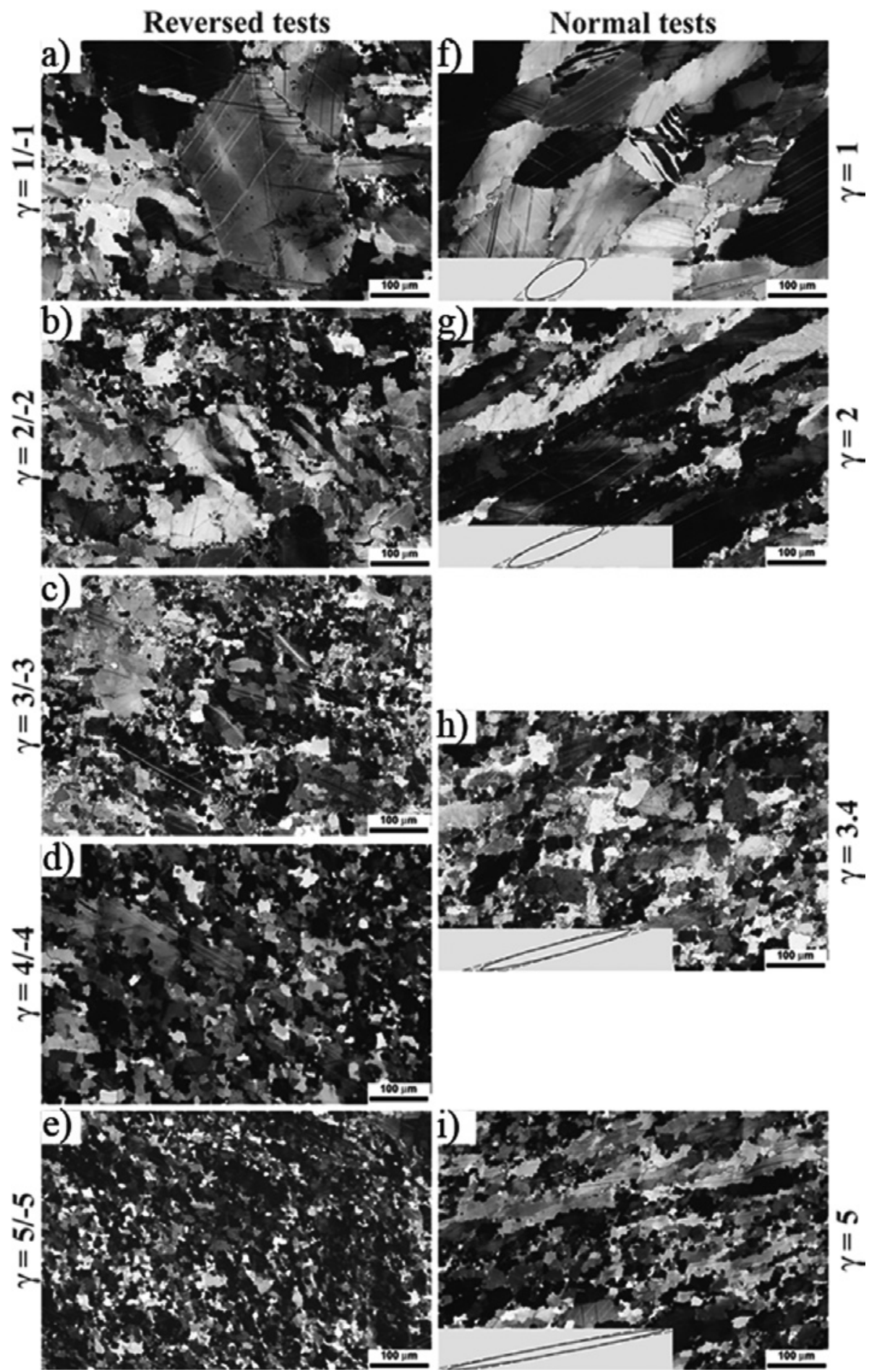

Fig. 4. Thin section photographs in crossed-polarized transmitted light of deformed type $I$ experiments compared with single stage deformed samples. The left column shows microstructures from reverted tests with the last deformation being sinistral. Right column shows microstructures from single stage tests. Amount of shear strain is indicated for each micrograph, strain ellipse is reported for the single stage tests.

Fig. 4 a \& b: after relatively small reverted shear strains the microstructure does not track the amount of imposed strain unlike in the case of single stage tests were grains develop a clear shape preferred orientation (Fig. $4 \mathrm{f} \mathrm{\&} \mathrm{g).}$

Fig. 4c, d, and e: large reverted shear strain with microstructures characterized by fine-grained dynamically recrystallized grains and few elongated relic grains. As in the case of single stage tests (Fig. 4 h \& i) a pervasive foliation develops, and the amount recrystallized grains increases with increasing shear strain.

366 C. Delle Piane \& L. Burlini 


\section{Macrostructures}

An overview of strain distribution at the sample scale is given in Figure 3. In both type I and type III experiments shear strain is homogeneously distributed across the specimen length as indicated by the inclination of the lines which were vertically scratched on the jacket perpendicular to the shear plane, serving as passive strain markers during straining. Particularly after the type I test the scratches returned almost shear-plane perpendicular after double symmetric torsion events. Type II experiments showed a strong shear strain partitioning at the specimen scale. Two strain domains could be distinguished, inside which deformation was homogeneous. In the top layer of the composite sample the reference lines form an angle $(\phi)$ of some $61^{\circ}$ with respect to the vertical axis of the cylinder, which corresponds to a shear strain of $\gamma=1.8$ according to the equation:

$$
\gamma=\tan \phi
$$

Within the lower layer of the specimen the angle $\phi$ was only some $12^{\circ}$, corresponding to a shear strain of $\gamma=0.2$.

\section{Microstructures}

\section{Type I experiments}

\section{$\gamma=1$ followed by $\gamma=1$ shear reversal}

Grains are nearly equant and do not show any shape or crystallographic preferred orientation after reversal (Fig. 4a). The grain size does not differ from that of the starting material. However, large grains show widespread evidence of intracrystalline deformation such as undulose extinction, bent lensoidal shaped twin lamellae and some subgrain development. Grain boundaries are straight to lobate with some small dynamically recrystallized grains starting to form a core and mantle structure around the larger grains. There is a tendency of the subgrains to have boundaries intersecting at angles of $90^{\circ}$ giving rise to a chessboard-like microstructure (Fig. 4a).

No sense of shear can be inferred from the analysis of the shape of the grains, and no pervasive foliation can be observed.

\section{$\gamma=2$ followed by $\gamma=2$ shear reversal}

The microstructure from strain reversal test is characterized by the coexistence of large relic grains, surrounded by small dynamically recrystallized calcite grains in a geometry resembling core and mantle structure (e.g. Valcke et al., 2007, Fig. 4b). The large grains are equant in shape with no preferred orientation and show abundant evidence of internal deformation like twins and undulose extinction. Twins are rather thick and generally not straight but bent and tapered in shape. The grain boundaries are very serrated and irregular often showing bulges and small new recrystallized grains. A pervasive foliation is not yet developed and no clear sense of shear can be inferred, in contrast with what observed on the microstructure from single stage experiment (Fig. 4g).

\section{$\gamma=3,4,5$ followed by equal amounts of shear reversal}

After larger reversed shear strains (runs PO586 and PO638) the initial microstructure becomes totally refreshed by dynamic recrystallization (Fig. 4c, d, and e). The recrystallized grains are about one order of magnitude smaller in size than the original grains; they are isometric in shape and seem to be
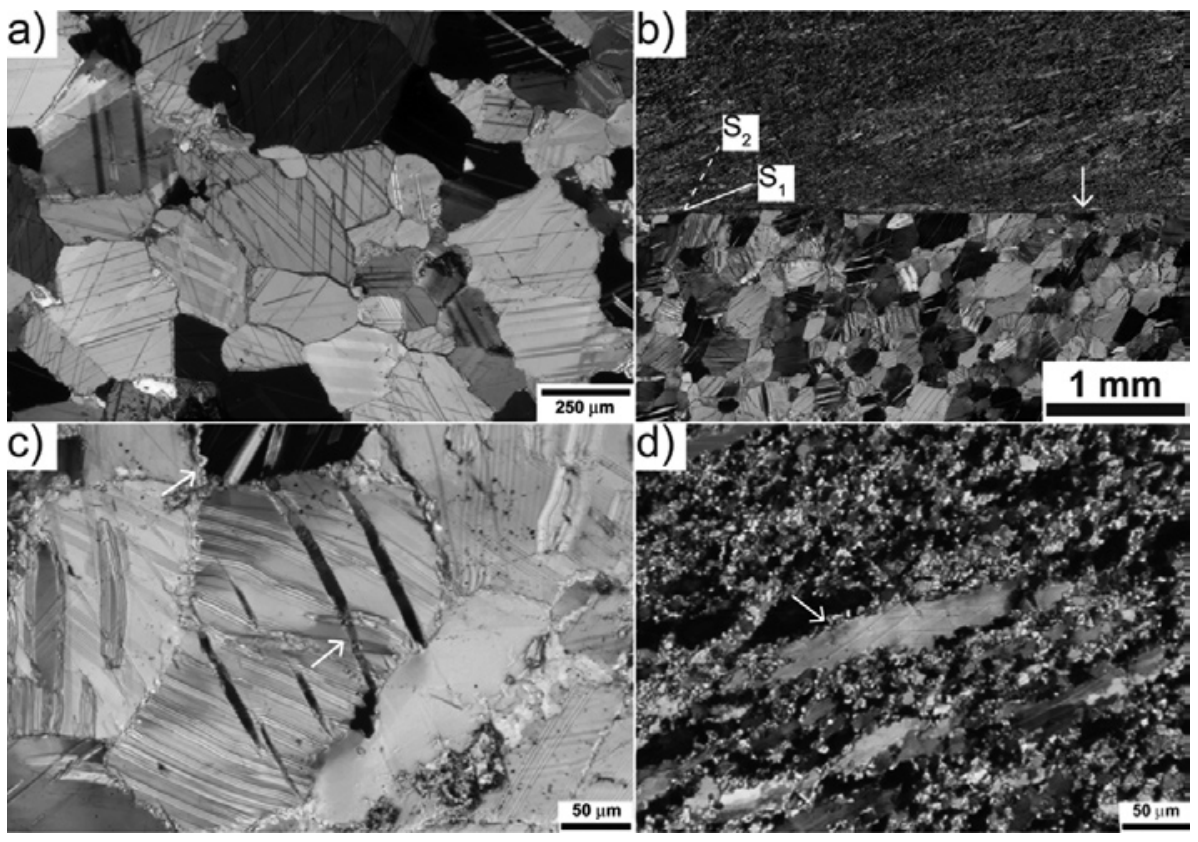

Fig. 5. Thin section photographs in crossed-polarized transmitted light of deformed type II experiment. (a) Starting material: Undeformed Carrara marble. (b) Overview of the composite specimen, white arrow indicating the discontinuity between the "as is" layer at the bottom and the previously deformed layer on top. Primary $\left(\mathrm{S}_{1}\right)$ and secondary $\left(\mathrm{S}_{2}\right)$ foliations are indicated with solid and dashed lines, respectively. (c) Close-up of the bottom layer: large grains display typical features of internal plastic deformation such as different generations of twin lamellae cutting each other (lower white arrow). Top white arrow indicates incipient dynamic recrystallization at grain boundaries. (d) Close-up of the top layer: Arrows indicate an elongated relic grain with the typical ribbon shape. Pervasive grain size reduction associated with dynamic recrystallisation is evident. 

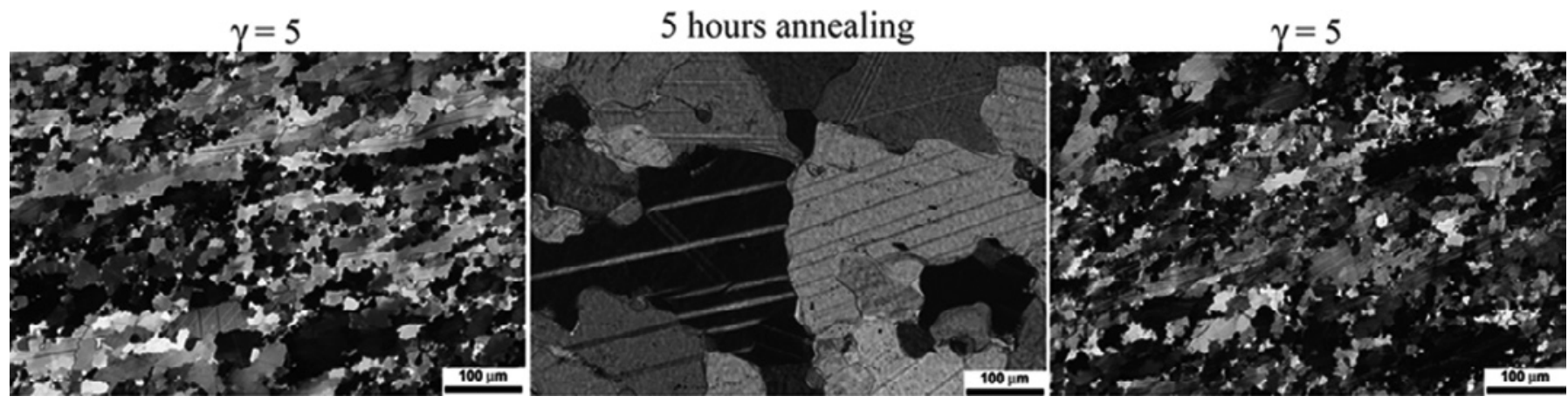

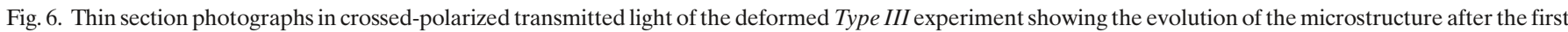
deformation event, after the 5 hours of static annealing and following the post-annealing deformation events. Scale bars are the same for all three micrographs.

free of internal deformation, as they do not display twins or undulose extinction. New dynamically recrystallized grains define a pervasive foliation, which is consistent with the direction of the last shearing event. Few relic grains are still present and assume a stretched and elongated ribbon shape with the long axis synthetically oriented with the flow direction imposed by the second shearing stage. Only after a "reversed" shear strain of 3 can the sense of shear of the latest deformation event be recognized.

\section{Type II experiments}

The striking features of this kind of experiments are the differences in the microstructure found in the two layers of marbles and the sharp and discrete separation between them. A careful analysis of the strain markers on the iron jacket reveals that, interestingly, the pre-existing discontinuity did not act as a slip surface. No offset of the passive marker line was found at the interface between the two layers on the jacket (Fig. 3). Also the microstructure shows the sharp contact between the two layers; and microstructure evolved independently with increasing shear strain (Fig. 5). The previously top layer deformed shows extensive grain size reduction associated with dynamic recrystallization and few relic grains in a ribbon shape, with the long axis inclined with the sense of shear. The ribbon grains show a foliation defined by the angle between the long axis and the shear zone boundary, a second foliation can be recognized as an alignment of grain boundaries of the newly recrystallized grains. The bottom layer ("as is") shows an almost undeformed microstructure. Large grains are still equant in shape showing evidence of internal plastic deformation such as undulose extinction and large bent twins (Fig. 5). As for the experiments of Barnhoorn et al. (2005) we did not observe significant grain growth in the coarse grained portion of the specimen.

\section{Type III experiments}

The microstructures from type III experiment are shown in Figure 6. After having been deformed subsequent to annealing,

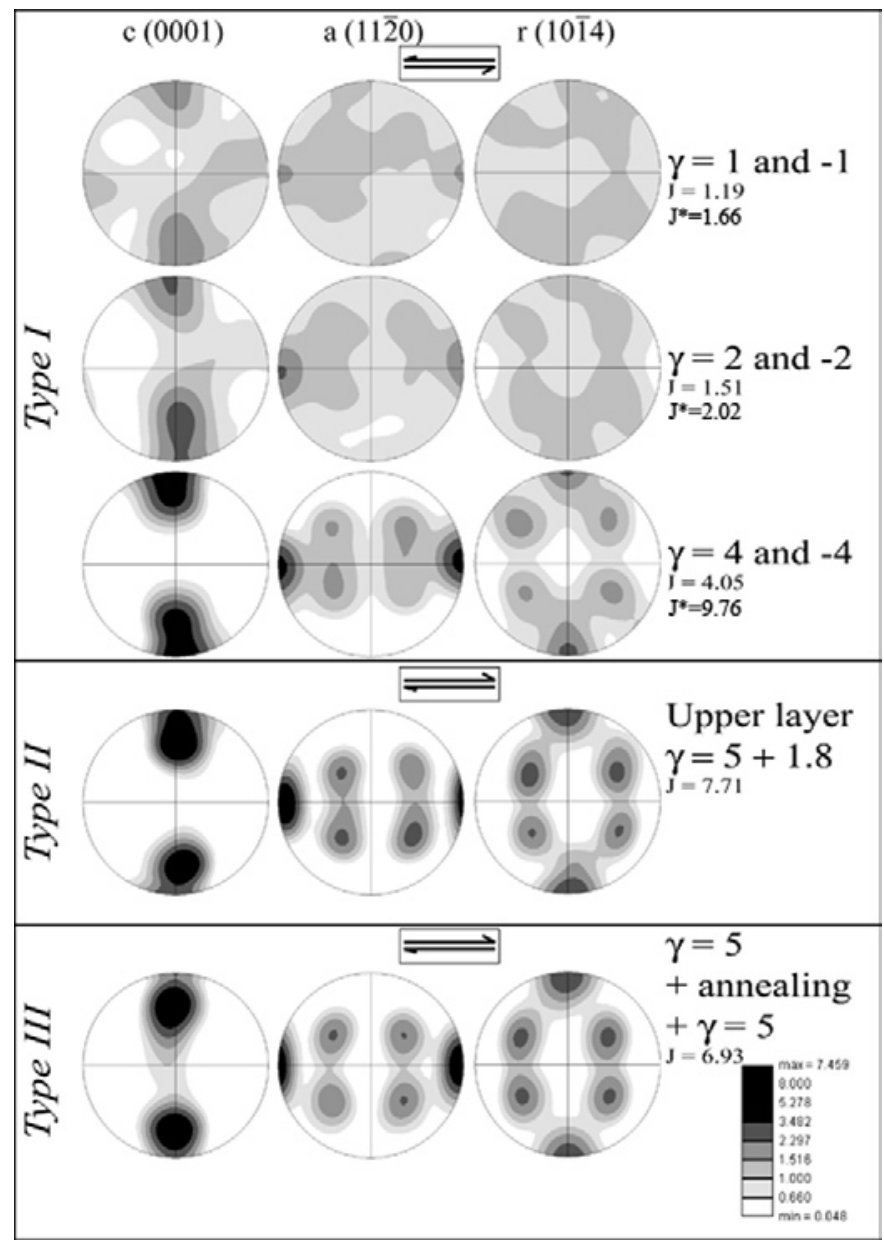

Fig. 7. (a) Contoured pole figures for type I experiments. Contouring after Gaussian convolution with a half width of $15^{\circ}$ and maximum expansion of $\mathrm{L}=32$ within the harmonic calculus. Lower hemisphere equal area projection, scale is expressed in log-scale multiples of random distributions. $\mathrm{J}^{*}$ are values reported by Pieri et al (2001b) from monotonic test on Carrara marble. (b) Pole figures for the upper part of the layered specimen. (c) CPO of deformedannealed-deformed specimen.

the marble shows extensive dynamic recrystallization resulting in grain-size refinement. A few large relic grains showing rib-

368 C. Delle Piane \& L. Burlini 

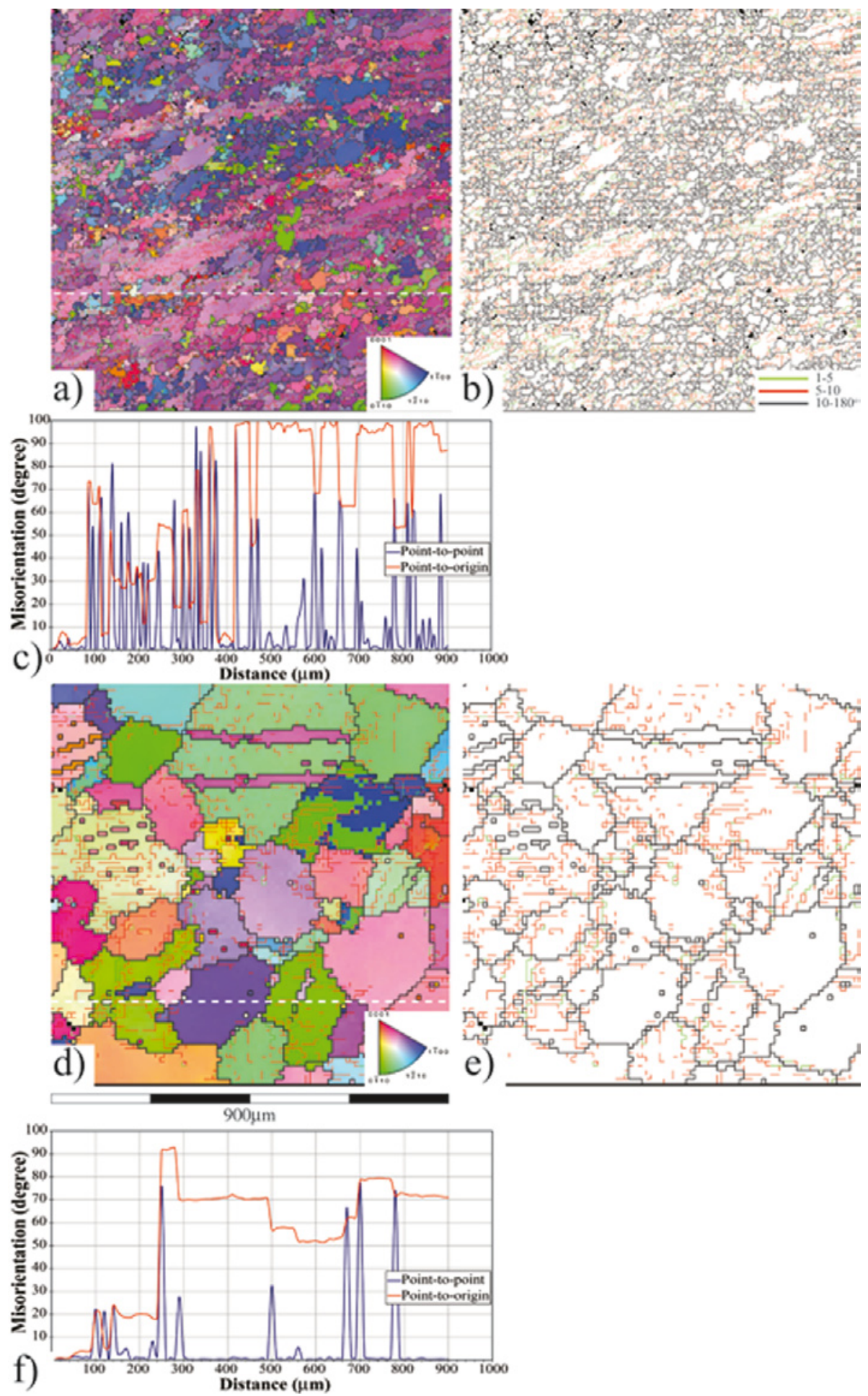

Fig. 8. (a) Inverse pole figure (IPF) map (lower right corner) of the scanned area from the upper layer of the composite sample. (b) Misorientation angle map obtained from the top layer of the composite layer. Elongated ribbon grains of calcite show intense internal substructures with misorientation angles between $1^{\circ}$ and $10^{\circ}$; whereas the small recrystallized grains are mostly internally non-deformed. (c) misorientation profile (see dashed white line in Figure 8a). The spiky jumps in angular orientation correspond to grain boundaries between dynamically recrystallized crystals. Note the regularly spaced undulations occurring within the relic ribbon grains. (d-e) IPF map and misorientation maps obtained from the bottom layer of the composite sample. Note the much larger grain size of the marble and the absence of dynamically recrystallized grains. (f) Misorientation profile (see dashed white line in Figure 8d). Minor variations in angular orientation are observed within the grains, mainly occurring at the grain boundaries.

bon shape are present, with the long axis obliquely oriented to bulk shear direction and with a synthetically inclined orientation in respect to the sense of shear. The ribbon-shaped grains show evidence of internal plastic deformation, such as undu- lose extinction, subgrains, and twin lamellae. When compared with the microstructure of a sample deformed to a shear strain of $\gamma=5$ with no annealing, type III microstructures show hardly any difference (see Fig. 4i). 

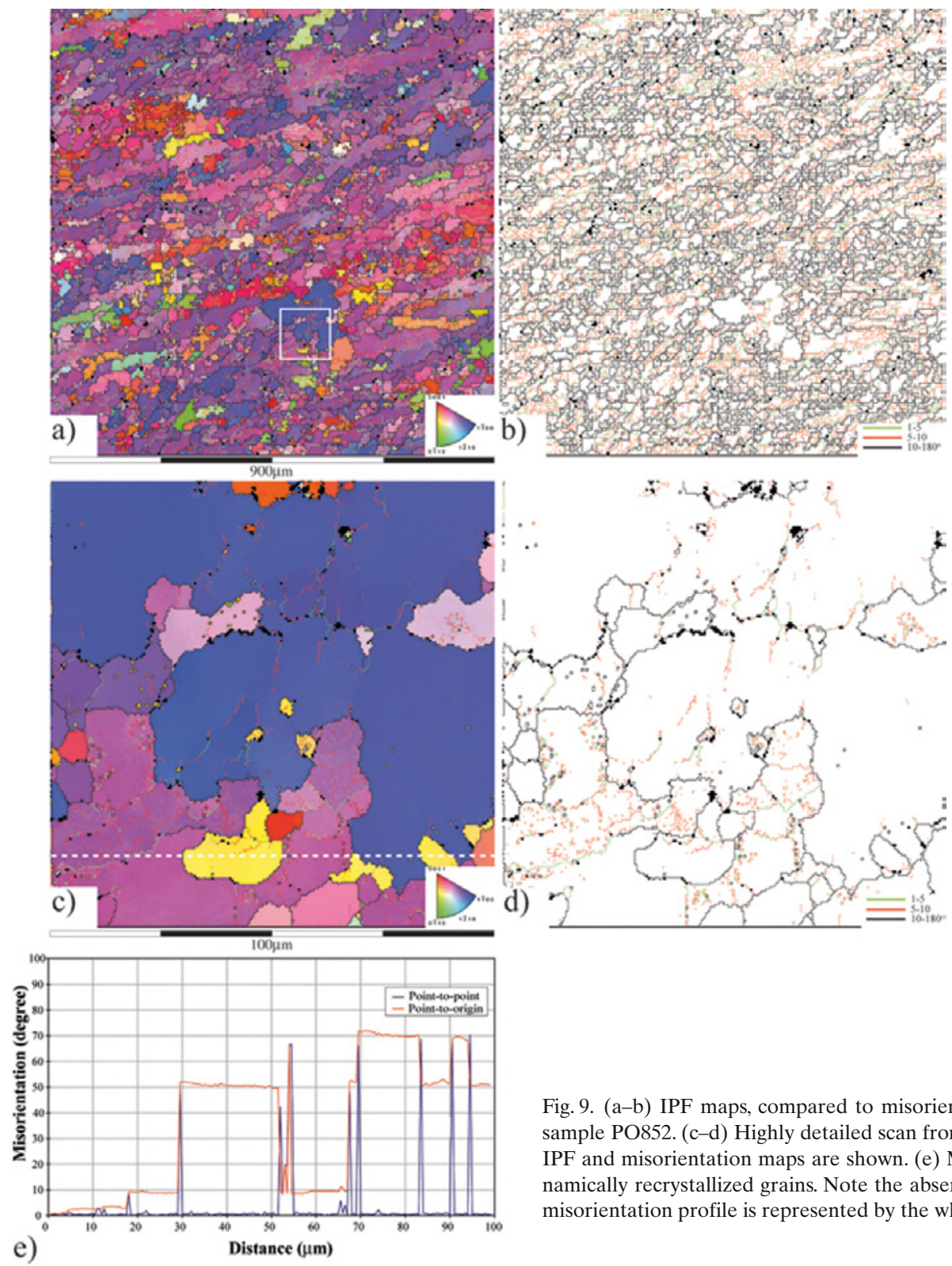

Fig. 9. (a-b) IPF maps, compared to misorientation angle maps obtained from selected areas of sample PO852. (c-d) Highly detailed scan from the area highlighted with a white box in Figure 9a. IPF and misorientation maps are shown. (e) Misorientation profile across a series of adjacent dynamically recrystallized grains. Note the absence of intragranular misorientation. The trace of the misorientation profile is represented by the white dashed line in Figure 9c.

\section{Crystallographic preferred orientation $(\mathrm{CPO})$}

\section{Type I experiments}

The CPO's of type I experiments are discussed in comparison with those obtained from normal monotonic experiments. As a general trend it can be observed that the main features are similar between the two experimental configurations. Reversed experiments show a concentration of the $c$-axes perpendicular to the shear direction; a small deviation from monoclinic symmetry is manifested by means of a small contouring tail oriented against the last shearing sense $(\gamma=2$, Fig. 7). With increasing reversed strain the $\mathrm{CPO}$ assumes a more ordered configuration: the $c$-axis form diffuse maxima normal to the shear direction and inclined at angle ranging between 60 and $90^{\circ}$ to the shear plane. One of the $a$-axis preferentially aligns parallel to the shear direction in agreement with the observations of Pieri et al. (2001) and Barnhoorn et al. (2004) for conventional torsion tests on Carrara marble. The $c$-axes maxima show a monoclinic symmetry manifested by a small inclination towards the last shearing sense. The "strength" of the reverted test fabric, calculated as $J$-index, increases with larger strains but always appears weaker than that form the CPO's of monotonic experiments (Fig. 7). 
Type II experiments

The CPO was only calculated for the highly strained top layer of the composite specimen. The texture is identical to that reported for the recrystallization CPO observed in highly strained Carrara marble (Pieri et al. 2001). The texture consists of symmetrically distributed $c$-axis maxima normal to the shear direction and inclined at about $60^{\circ}$ to the shear plane. One of the $a$-axes lies parallel to the shear direction. The overall symmetry of the CPO is orthorhombic. The value of the $J$ index is comparable to that reported in previous studies.

EBSD measurements on selected areas of the specimens were made to obtain detailed maps of the crystallographic orientations with a resolution allowing visualizing intragranular misorientations. The results of the detailed scans are presented in Figure 8 as misorientation maps. Comparison of the maps ob- tained from the two layers allowed for making a series of observations. The top layer shows intense grain size reduction by dynamic recrystallization. Newly formed small grains are equant in shape and strain free. The inverse pole figure map is dominated by colours ranging from blue to purplish-blue, indicating the most favourable orientation for slip on $\mathrm{r}<\mathrm{a}>$ and $\mathrm{c}<\mathrm{a}>$. Relic grains are in a ribbon shape with the long axis synthetically oriented with the sense of shear; they show intense internal deformation manifested by incipient but already organized subgrain boundaries with misorientations angles of up to $10^{\circ}$ with respect to the host grain. Misorientation profiles traced parallel to the shear plane reveal rather spiky curves when intersecting relics ribbon grains, and flat curves (internal misorientation of about $1^{\circ}$ ) in the interiors of the newly recrystallized grains.

The bottom layer of the sample is almost undeformed: large calcite grains are equant in shape with straight or slightly

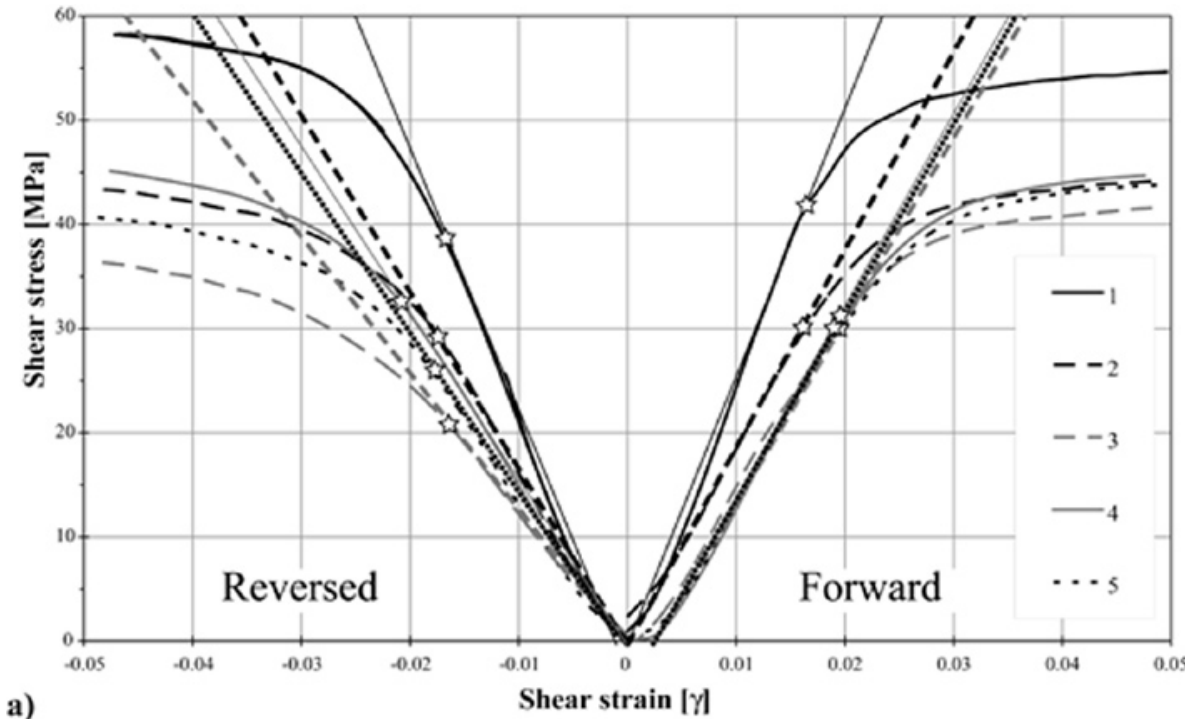

a)

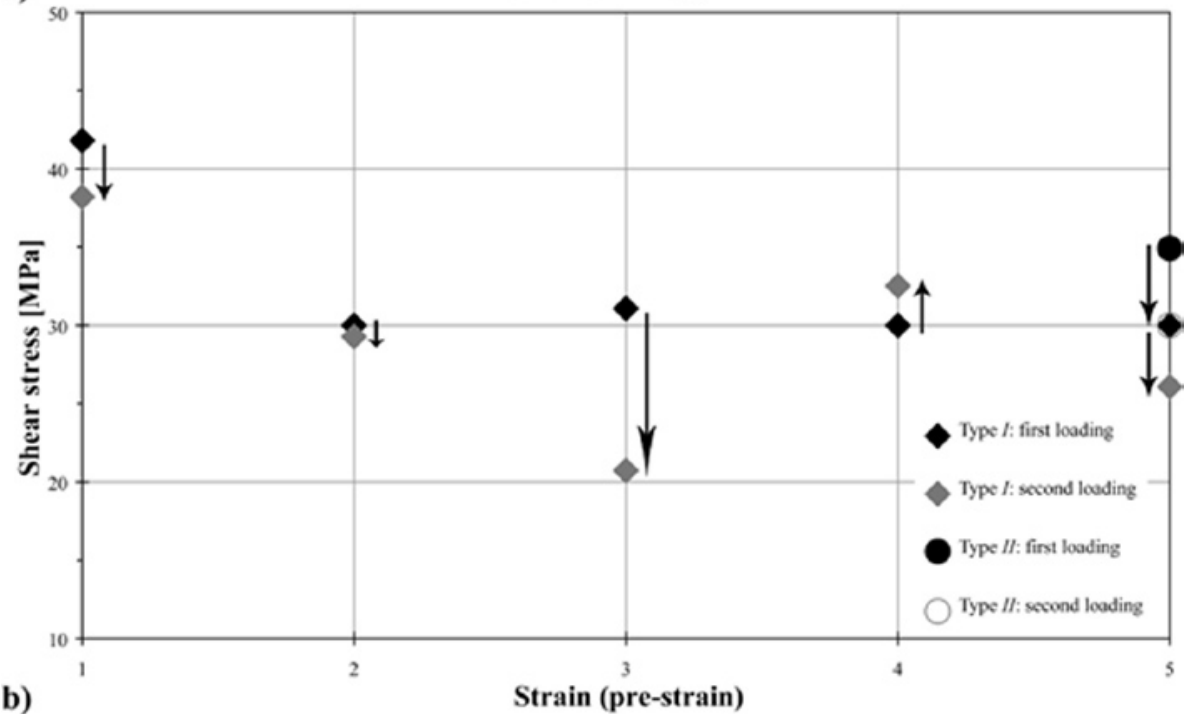

Fig. 10. Summary of mechanical comparison upon stress reversal effects. a) The shear stress of type $I$ experiments is plotted as a function of shear strain at low strains. Forward tests are reported on the right half of the plot while the shear reversal test is represented in the left half. The yield point for each experiment is highlighted with a star at the point at which the stress-strain response departs from linearity. The legend indicates the amount of shear strain attained before stress reversal (pre-strain). b) Difference of yield stress between forward and reverse loading plotted as a function of pre-strain for type $I$ and type $I I I$ experiments. Arrows pointing downwards indicate a decrease in yield stress upon stress reversal (Bauschinger effect); arrows pointing upwards indicate an increase in yield stress. 
curved grain boundaries. Twins can be observed in the largest grains. No subgrains have developed yet but small intracrystalline deformation is manifested through small rectilinear segments with misorientations of up to $10^{\circ}$ with respect to the parent grain, mostly lying parallel to the shear direction. Misorientation profiles traced parallel to the shear plane indicate only minor deviations $\left(<5^{\circ}\right)$ within single grains.

\section{Type III experiments}

The texture consists of symmetrically distributed $c$-axis maxima normal to the shear direction and inclined at about $60^{\circ}$ to the shear plane, a weak girdle normal to the shear direction links the two maxima. One of the $a$-axes lies parallel to the shear direction. The overall symmetry of the CPO is orthorhombic. Despite the larger strain to which the sample has been exposed, the $J$ index value is lower than that reported for Carrara marble experimentally sheared up to $\gamma=10$, highlighting the effect of the annealing stage in texture randomization (e.g. Barnhoorn et al., 2005) to that reported in previous studies.

Detailed scans $(100 \times 100 \mu \mathrm{m} ; 0.5 \mu \mathrm{m}$ step size $)$ were used to investigate the internal structure of the dynamically recrystallized grains. The misorientation angle maps and profile are presented in Figure 9 and clearly indicate that misorientation angles between new grains can be as large as $40^{\circ}$ over a distance of about $1 \mu \mathrm{m}$. The inner part of the new grains, on the other hand, is almost strain free and only shows minor variations, with point-to-point misorientations of about $1^{\circ}$. This is in agreement with what was measured in naturally deformed calcite marble by Bestmann \& Prior (2003).

\section{Discussion}

\section{Effect of strain}

The mechanical behaviour under reversed loading has been studied for a variety of materials in metallurgy, and particular

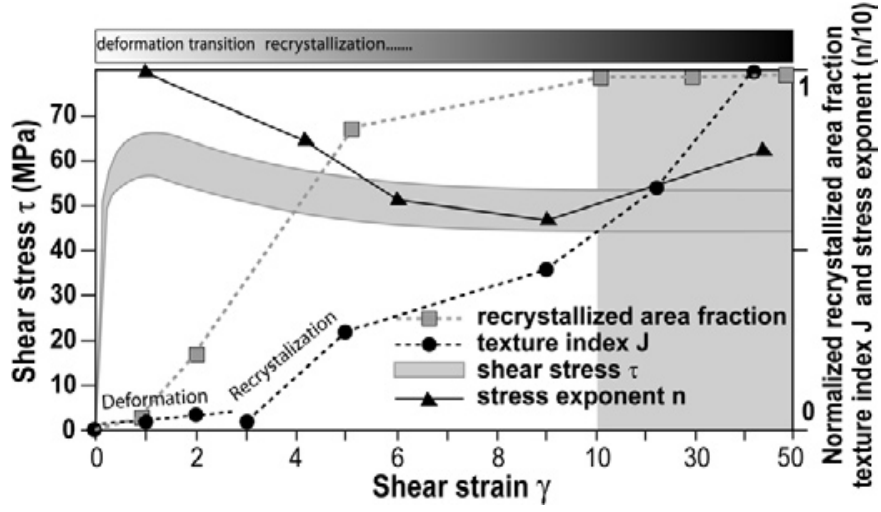

Fig. 11. Rheological and microstructural evolution of Carrara marble deformed in torsion at $1000 \mathrm{~K}$. Shear stress $\tau$, texture index $J$, stress exponent $n$ and area fraction of recrystallized grains are plotted as a function of shear strain $\gamma$. attention was paid to the decrease in yield stress after reloading, a phenomenon known as the Bauschinger effect (Rauch et al. 2007). The Bauschinger effect is normally associated with conditions where the yield strength of a metal decreases when the direction of strain is changed (Rauch et al.2007). It is a general phenomenon found in most polycrystalline metals and has important implications for construction materials undergoing cyclic loadings. The macroscopic effect of a strain path change is commonly associated with the occurrence of a dislocation structure in the material and its adaptation to the new loading. The Bauschinger effect is usually related to the degradation and reappearance of the dislocation structure under stress reversal (Viatkina et al. 2007).

In agreement with what was observed in metals, the plastic behaviour of Carrara marble after strain reversal is slightly different from that of a monotonic test. In particular, the yield stress of the reverted samples is somewhat lower (between 2 and $33 \%$ ) than that of the monotonic tests, with the exception of test PO638 in which after a shear strain of $\gamma=4$ the reverted yield stress was found to be few MPa higher ( $8 \%$ ) in respect to that reached during the first loading (Fig. 10).

During reverted tests a variation in yield stress between the two kinematically opposite loadings was systematically observed. No correlation could be found between the difference in value of yield stresses of the first and second loading and the amount of shear strain the samples underwent during the first deformation stage (Fig. 10b). Further experiments would be required to establish a relationship.

At large reversed strain the flow stress is as before the reversal. This implies that the mechanical state of the sample is only moderately affected by the reversal of the strain field.

After elastic loading, at the onset of weakening, once plastic processes have become active in accommodating strain, the marble is permanently softened regardless of the shearing sense. This effect may facilitate strain localization during plastic re-activation of already formed geological structures, as for rocks that experience plastic deformation, the mechanical response depends on their deformation history not just on their current stress state. Specifically, experiments in Carrara marble have shown that, the yield stress in the reverse direction is generally lower than in the undeformed state, therefore plastic (permanent) strain is facilitated.

\section{Effect of CPO vs. grain size reduction}

These experiments as well as previous torsion experiments on Carrara marble have demonstrated that the peak stress reached at around $\gamma=1$ at $1000 \mathrm{~K}$ and $3 \times 10^{-4} \mathrm{~s}^{-1}$ strain rate, is followed by a weakening of about $20-25 \%$. During this stage, both microstructure and CPO change drastically. According to Pieri et al. (2001) and Barnhoorn et al. (2004) the type of texture changes from deformation texture to recrystallization texture. As reported in Figure 11, the intensity of the CPO begins to increase almost immediately (deformation fabric), 
as is testified by the increasing $J$ index. The symmetry of this fabric is monoclinic. After a shear strain of about $\gamma=2$, the $J$ index drops, owing to the change in type of CPO from deformation to recrystallization. Afterwards, the recrystallization fabric increases very steeply up a shear strain of about $\gamma=10$, and then less fast until the highest experimentally attained shear strain of $\gamma=50$ is reached (Barnhoorn et al. 2004). On the other hand, recrystallization at the grain boundaries begins already at a shear strain of $\gamma=2$. This effect is immediately detected by a strength decrease at the beginning of weakening. The weakening ends at about $\gamma=5$ when the rock is more than $80 \%$ recrystallized. This implies that grain size reduction is responsible for weakening. As pointed out by Evans, (2005), current laboratory based rheological studies do not include the effect of lattice preferred orientation known as geometrical softening, although it is widely known that minerals are largely anisotropic. It is therefore likely that the strength of a textured rock may vary from that of a rock with a random crystal distribution.

In conventional rock testing, however, the weakening effects of dynamic recrystallization and grain size reduction overlap with those induced by geometrical softening. With out type $I I$ tests we can separate the contribution of the CPO from that of the recrystallization-induced grain size reduction. The sample deformed up to $\gamma=5$, i.e. after weakening was complete, was it was annealed for 5 hours in order to allow considerable grain growth up to 52 microns in average. This is an order of magnitude larger than the grain size before the annealing, but still half or one third of the grain size of the undeformed Carrara marble. This annealed sample is therefore similar to the original Carrara marble in grain size, but possesses a strong CPO $(J$ index $\sim 10)$, with a pattern very similar to that reached after pre-annealing deformation. During post-annealing deformation the sample yielded at $30 \mathrm{MPa}$, i.e. $14 \%$ lower than the $35 \mathrm{MPa}$ yield stress observed in previously undeformed Carrara Marble that does not yet possess a CPO. At peak stress conditions the textured marble is only $7 \%$ weaker than the non-textured marble. Since the total weakening is between 20 and $25 \%$, the effect of grain size reduction towards the overall weakening is predominant over that achieved by geometrical weakening. Roughly, geometrical weakening contributes to about one third, while recrystallization and grain size reduction cause to two thirds of the total amount of weakening.

\section{Conclusions and geological implications}

Microstructures of deformed rocks represent a fundamental link between experimental rock deformation studies, experimentally based flow laws and deformation associated with large-scale tectonic processes. Even though, many problems exist with the comparison of natural observations to laboratory data (e.g. Paterson 2001), an improved understanding of deformation driven microstructural processes can shed light on the interpretation of natural microstructures from carbonate mylonites in terms of creep mechanisms and therefore on the history of the rock.

The experiments we have performed on Carrara marble at conditions similar to those previously reported in the works of Pieri et al. (2001a; b), and Barnhoorn et al. (2004), (1000 K, $300 \mathrm{MPa}$ and $310^{-4} \mathrm{~s}^{-1}$ ) have important implications for the interpretation of naturally deformed carbonate mylonites. The results, even though still exploratory, are particularly relevant for cases of tectonic reactivation, whereby rocks are deformed in multiple events under similar physical conditions (e.g. Molli \& Heilbronner 1999; Molli et al. 2000), and they allow addressing geologically oriented questions:

a) What microstructural information can be inferred from a rock exposed to multiple deformation events? After a reversed shear strain of $\gamma=2$ or less, our samples show microstructural features which are normally associated with low amounts of strain, such as twin lamellae, undulose extinction, and incipient recrystallization at grain boundaries. Overall, at the microstructural level, the sample seems to have no record of the absolute amount of strain it underwent.

b) What is the sense of shear recorded by a rock that underwent multiple deformation events? After a reversed shear strain of $\gamma=2$ or less no sense of shear can be detected after reversal, since the microstructure is perfectly recovered (see Fig. 4). After a reversed shear strain of 3 or larger, only the latest sense of shear is recognized.

c) Is it possible to use the CPO to infer the sense of shear in the case of shear reversal? The CPO, that at $\gamma=1$ and 2 is typically asymmetric after a single shear event, becomes symmetric after reversing shear strain. This CPO cannot be used to infer the sense of shear. On the other hand, after a reversed shear strain of 3, a minor asymmetry in the c axis distribution could eventually be used in order to infer the sense of shear.

d) How important is geometric softening? Geometric softening contributes to about one third of the total weakening of the deformed rock. This means that a textured rock will always be weaker than the protolith in the same reference frame.

e) How important is the contribution of grain refinement towards weakening? For our tests we evaluated that grain size reduction induced by dynamic recrystallization contributes to about two thirds of total weakening. This means that a recrystallized fine grained rock is always weaker than the protolith, since the diffusion accommodated processes are enhanced with respect to the coarse grained starting material. This portion is predominant on the CPO effect.

In conclusion, previously deformed rock is weaker than its protolith by about $20 \%$. This means that a deformed mylonite will be the locus for reactivation during a second deformation event. 


\section{Acknowledgements}

Research was supported by ETH grant TH 1/03-3/2704.5. Images of the monotonic microstructures were taken from samples deformed by Auke Barnhoorn during his Ph.D. at ETH. Robert Hoffmann guaranteed continuous support in the lab; Frowin Pirovino is thanked for careful thin section preparation. The Electron Microscopy ETH-Zurich (Emez) gently allowed the use of the SEM equipment. Karsten Kunze provided valuable suggestions and insights into texture analysis. C.D.P. thanks Siska Valcke for suggesting some "heavy metal" readings on stress reversal. The authors enjoyed frequent "microstructural" conversation with Chris Wilson during his stay at the ETH, as well as with Renee Heilbronner, Hans de Bresser and Jan Ter Heege. We thank Marco Herwegh and Julian Mecklenburgh for their careful reviews and Stefan Schmid for his patient editorial work, which significantly improved the original manuscript.

\section{REFERENCES}

Austin N., Evans, B., Herwegh, M. \& Ebert, A. 2008: Strain Localization in the Morcles Nappe (Helvetic Alps, Switzerland). Swiss Journal of Geosciences 101, 341-360.

Barnhoorn, A., Bystricky, M., Burlini, L. \& Kunze, K. 2004: The role of recrystallisation on the deformation behaviour of calcite rocks: large strain torsion experiments on Carrara marble. Journal Of Structural Geology 26, 885-903.

Barnhoorn, A., Bystricky, M., Burlini, L. \& Kunze, K. 2005: Post-deformational annealing of calcite rocks. Tectonophysics 403, 167-191.

Bestmann, M., Kunze, K. \& Matthews, A., 2000: Evolution of a calcite marble shear zone complex on Thassos Island, Greece: Microstructural and textural fabrics and their kinematic significance. Journal of Structural Geology 22, 1789-1807.

Bestmann, M., \& Prior, D.J. 2003: Intragranular dynamic recrystallization in naturally deformed calcite marble: diffusion accommodated grain boundary sliding as a result of subgrain rotation recrystallization. Journal of Structural Geology 25, 1597-1613.

Burg, J.P., Wilson, C.J.L. \& Mitchell, J.C. 1986: Dynamic Recrystallization and Fabric Development During the Simple Shear Deformation of Ice. Journal of Structural Geology 8, 857-870.

Burkhard, M. 1990: Ductile deformation mechanisms in micritic limestones naturally deformed at low temperatures $\left(150-350{ }^{\circ} \mathrm{C}\right)$. In: Knipe, R.J. \& Rutter, E.H. (Eds): Deformation Mechanisms, Rheology and Tectonics. Geological Society of London Special Publication 54, 241257.

Burkhard, M. 1993: Calcite twins, their geometry, appearance and significance as stress-strain markers and indicators of tectonic regime: a review. Journal of Structural Geology 15, 351-368.

Bystricky, M., Kunze, K., Burlini, L. \& Burg, J.-P. 2000: High shear strain of olivine aggregates: rheological and seismic consequences. Science 290, 1564-1567.

De Bresser, J.H.P., Peach, C.J., Reijs, J.P.J. \& Spiers, C.J. 1998: On dynamic recrystallization during solid state flow: Effects of stress and temperature. Geophysical Research Letters 25, 3457-3460.

De Bresser, J.H.P., Ter Heege, J.H. \& Spiers, C.J. 2001: Grain size reduction by dynamic recrystallization: can it result in major rheological weakening? International Journal of Earth Sciences 90, 28-45.

Dellangelo, L.N. \& Tullis, J. 1989: Fabric Development in Experimentally Sheared Quartzites. Tectonophysics 169, 1-21.

Ebert, A., Herwegh, M., Evans, B., Pfiffner, A., Austin, N. \& Vennemann, T. 2007: Microfabrics in carbonate mylonites along a large-scale shear zone (Helvetic Alps). Tectonophysics 444, 1-26.

Evans, B. 2005: Creep constitutive laws for rocks with evolving structure. In: Bruhn D. \& Burlini L. (Eds): High-Strain Zones: Structure and Physical Properties. Geological Society of London. Special Publication 245, 329-346.

Heilbronner, R. \& Tullis, J. 2002: The effect of static annealing on microstructures and crystallographic preferred orientations of quartzites experimentally deformed in axial compression and shear. In: De Meer, S. Drury, M., De Bresser, J.H.P., Pennock, G.M. (Eds): Deformation
Mechanisms, Rheology and Tectonics: Current Status and Future Perspectives. Geological society of London, Special publication 200, $191-$ 218.

Herwegh, M. \& Handy, M.R. 1996: The evolution of high-temperature mylonitic microfabrics: evidence from simple shearing of a quartz analogue (norcamphor). Journal of Structural Geology 18, 689-710.

Herwegh, M., Handy, M. R \& Heilbronner R. 1997: Temperature- and strainrate-dependent microfabric evolution in monomineralic mylonite: evidence from in situ deformation of norcamphor. Tectonophysics 280 , 83-106.

Herwegh, M. \& Handy, M.R. 1998: The origin of shape preferred orientations in mylonite: inferences from in-situ experiments on polycrystalline norcamphor. Journal of Structural Geology 20, 681-694.

Means, W.D. \& Xia, Z., G. 1981: Deformation of crystalline materials in thin section. Geology 9: 538-543.

Molli, G. \& Heilbronner, R. 1999: Microstructures associated with static and dynamic recrystallization of Carrara marble (Alpi Apuane, NW Tuscany, Italy). Geologie en Mijnbouw 78, 119-126.

Molli, G., Conti, P., Giorgetti G., Meccheri, M. \& Oesterling, N. 2000: Microfabric study on the deformational and thermal history of the Alpi Apuane marbles (Carrara marbles), Italy. Journal of Structural Geology 22, 1809_ 1825.

Park, Y., Ree, J.H. \& Kim, S. 2001: Lattice preferred orientation in deformedthen-annealed material: observations from experimental and natural polycrystalline aggregates. International Journal of Earth Sciences 90, 127-135.

Paterson, M.S. \& Olgaard, D.L. 2000: Deformation tests to large shear strains in torsion. Journal of Structural Geology 22, 1341-1358.

Paterson, M.S. 2001: Relating experimental and geological rheology. International Journal of Earth Sciences 90, 157-167.

Pieri, M., Burlini, L., Kunze, K., Olgaard, D. \& Stretton, I. 2001a: Dynamic Recrystallization of Carrara Marble during high temperature torsion experiments. Journal of Structural Geology 23, 1393-1413.

Pieri, M., Kunze, K., Burlini, L., Stretton, I., Olgaard, D., Burg, J.-P. \& Wenk, R.H. 2001b: Texture development in calcite through deformation and dynamic recrystallization during torsion to large strains. Tectonophysics 330 , 119-140.

Poirier, J.P. 1985: Creep of crystals. High-temperature deformation processes in metals, ceramics and minerals. Cambridge University Press.

Rauch, E.F., Gracio, J.J. \& Barlat, F. 2007: Work-hardening model for polycrystalline metals under strain reversal at large strains. Acta Materialia 55, 2939-2948.

Ree, J.H. \& Park, Y. 1997: Static recovery and recrystallization microstructures in sheared octachloropropane. Journal of Structural Geology 19, 1521-1526.

Rutter, E.H. \& Brodie, K.H. 1988: The Role of Tectonic Grain-Size Reduction in the Rheological Stratification of the Lithosphere. Geologische Rundschau 77(1), 295-307.

Rutter, E.H., Casey, M. \& Burlini, L. 1994: Preferred crystallographic orientation development during the plastic and superplastic flow of calcite rocks. Journal of Structural Geology 16, 1431-1446.

Rutter, E.H. 1995: Experimental study of the influence of stress, temperature, and strain on the dynamic recrystallization of Carrara marble. Journal of Geophysical Research 100, 24651-24663.

Schmid, S.M. 1982: Microfabric studies as indicators of deformation mechanisms and flow laws operative in Mountain Building. In: Hsü, K.J. (Ed.): Mountain Building Processes. Academic Press London, 95110 .

Schmid, S.M., Panozzo, R. and Bauer, S. 1987: Simple shear experiments on calcite rocks: Rheology and microfabric. Journal of Structural Geology 9, 747-778.

Ter Heege, J., De Bresser, J.H.P. \& Spiers, C.J. 2002: The influence of dynamic recrystallization on the grain size distribution and rheological behaviour of Carrara marble deformed in axial compression. In: De Meer, S. Drury, M., De Bresser, J.H.P., Pennock, G.M. (Eds): Deformation Mechanisms, Rheology and Tectonics: Current Status and Future Perspectives. Geological society of London, Special publication 200, $331-353$ 
Twiss, R.J. 1976: Structural Superplastic Creep and Linear Viscosity in Earths Mantle. Earth and Planetary Science Letters 33, 86-100.

Valcke, S. L.A., Drury, M.R., de Bresser, J.H.P. \& Pennock, G.M. 2007: Quantifying Heterogeneous Microstructures: Core and Mantle Subgrains in Deformed Calcite. Materials Science Forum 550, 307-312.

Viatkina, E.M., Brekelmans, W.A.M. \& Geers, M.G.D. 2007: Modelling the evolution of dislocation structures upon stress reversal. International Journal of Solids and Structures 44, 6030-6054.
Zhang, S.Q. \& Karato, S. 1995: Lattice Preferred Orientation of Olivine Aggregates Deformed in Simple Shear. Nature 375, 774-777.

Manuscript received November 15, 2008

Revision accepted March 15, 2008

Published Online first July 23, 2008

Editorial Handling: S. Schmid \& S. Bucher 